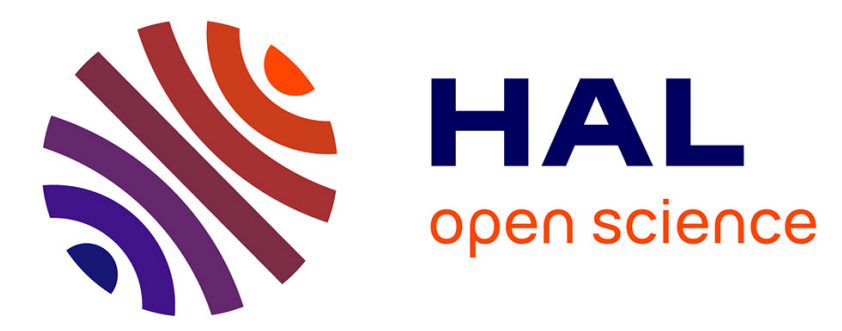

\title{
Towards modelling the activity of design: An observational study on a specification stage
}

Willemien Visser

\section{To cite this version:}

Willemien Visser. Towards modelling the activity of design: An observational study on a specification stage. IFAC/IFIP/IEA/IFORS Conference on Man-Machine Systems. Analysis, Design and Evaluation, IFAC/IFIP/IEA/IFORS, Jun 1988, Oulu, Finland. hal-00641401

\section{HAL Id: hal-00641401 \\ https://hal.inria.fr/hal-00641401}

Submitted on 15 Nov 2011

HAL is a multi-disciplinary open access archive for the deposit and dissemination of scientific research documents, whether they are published or not. The documents may come from teaching and research institutions in France or abroad, or from public or private research centers.
L'archive ouverte pluridisciplinaire $\mathbf{H A L}$, est destinée au dépôt et à la diffusion de documents scientifiques de niveau recherche, publiés ou non, émanant des établissements d'enseignement et de recherche français ou étrangers, des laboratoires publics ou privés. 
This text is the author's version of

Visser, W. (1988, 14-16 June). Towards modelling the activity of design: An observational study on a specification stage. Preprints of the IFAC/IFIP/IEA/IFORS Conference Man-Machine Systems. Analyisis, Design and Evaluation (Volume 1). Oulu, Finland, 14-16 June 1988.

TOWARDS MODELLING THE ACTIVITY OF DESIGN:

AN OBSERVATIONAL STUDY ON A SPECIFICATION STAGE

\author{
Willemien VISSER \\ Projet de Psychologie Ergonomique pour l'Informatique, INRIA \\ Domaine de Voluceau, Rocquencourt, B.P. 105, 78153 Le Chesnay Cedex, France
}

\begin{abstract}
We conducted three weeks full time observations on a mechanic participating in a real, complex, industrial design project. The task observed was the specification of the operative part of an automatized machine tool installation. The method of simultaneous verbalization was used for collecting data on the mechanic's design activity. In this article, we present the general architecture of a part of a model of this activity as we derived it from the observations we analyzed until now. We divided the mechanic's solution space in different goal spaces. Control procedures formalized as production rules govern the transitions within a goal space (between the procedures in it) and between different goal spaces. The central articulation of goal spaces was presented as being hierarchical, following the mechanic's description of his plan, but control rules for goal changes abandoning this plan were formulated to account for our observations of goal deviation. Design appears not to be an exclusively hierarchically organized plan-guided activity. This result leads us to favor an opportunistic model which can incorporate the possibility for plan-guided contributions without being exclusively governed by such a plan.
\end{abstract}

Keywords. Design activity, Modelling, Cognitive systems, Specification, Machine tools.

Résumé. Des observations ont été menées auprès d'un concepteur mécanique tout au long de sa tâche de définition des spécifications fonctionnelles de la partie opérative d'une installation automatisée de machine-outil. Le concepteur décrivait son activité comme suivant un plan structuré hiérarchiquement. Ce plan, cependant, ne rend pas compte de son activité qui est en fait organisée de façon opportuniste. Le concepteur suit son plan tant que celui-ci est intéressant du point de vue du coût cognitif des actions proposées. Dès que d'autres actions sont plus intéressantes, il dévie de son plan pour procéder à celles-ci.

Cet article présente l'architecture générale d'une partie d'un modèle de cette activité basée sur l'analyse d'une partie des observations. L'espace de solution du concepteur est divisé en différents espaces liés aux buts poursuivis. Des procédures de contrôle formalisées comme des règles de production gouvernent les transitions à l'intérieur d'un espace lié à un but (entre les procédures dans l'espace) et entre différents espaces liés à des buts. L'articulation centrale des espaces liés à des buts est présenté comme une structure hiérarchique, selon la description de son plan par le concepteur, mais des règles de contrôle pour les changements de but conduisant à des déviations de ce plan ont été formulées pour rendre compte des déviations observées.

La conclusion que la conception ne semble pas être une activité organisée de façon exclusivement hiérarchique favorise un modèle opportuniste qui peut incorporer des possibilités de contributions guidées par un plan, sans être gouverné exclusivement par un tel plan.

Mots-clés. Activité de conception, Spécification, Planification, Organisation opportuniste, Modélisation, Contrôle, Observation, Etude de terrain, Analyse de protocoles, Machine-outil automatisée 
This text is the author's version of

Visser, W. (1988, 14-16 June). Towards modelling the activity of design: An observational study on a specification stage. Preprints of the IFAC/IFIP/IEA/IFORS Conference Man-Machine Systems. Analyisis, Design and Evaluation (Volume 1). Oulu, Finland, 14-16 June 1988.

\section{INTRODUCTION}

Until today studies of problem-solving activity have been concerned mostly with the resolution of "well defined" (Eastman, 1969) or "well structured" (Simon, 1973) problems. The two characteristics of this type of problem which are most relevant for our purpose are

- the existence of "a definite criterion for testing any proposed solution" (Simon, 1973, p. 183);

- the specification, "either explicitly or by some agreed upon formal convention" (Eastman, 1969, p. 669), of the initial problem state, the goal state and the legal operators available to bridge the gap between these two states.

Even if the distinction between well structured and ill structured problems can be considered to be vague, fluid and a matter of degree (see both autors cited above), design problems are, by definition, of the second type:

- their solutions are more or less "acceptable" or "satisfying", they are not either "correct" or "incorrect";

- so, different solutions are acceptable, one being possibly more satisfying on one dimension, another on another dimension;

- a part of their problem specification is lacking and an important part of their solution consists in specifying this missing information;

- an explicit definition of an acceptable goal state is not given at the start, but has often to be derived from reactions to proposed intermediate solution states.

Design being a special form of problem solving, the study of its underlying psychological activity is interesting and important for several reasons:

- it may enrich the knowledge we possess on problem solving by possibly disclosing cognitive processes which are different in nature or used in different configurations compared to the ones we know already to be at work in "classical" problem solving;

- it is required for the development of intelligent assistance tools.

If the quantity of research done in this domain is not important (especially compared to the attention "well defined" problem solving has received), several interesting studies have been done (for a critical presentation, see Bisseret, 1987; Carroll and Rosson, 1985). However all have been conducted on more or less artificial problems to be solved in a limited context:

- most subjects studied have been students;

- the majority of the presented problems have been more or less simplified "school" problems;

- in general, the observations have been conducted in a restricted setting, most often in the psychological laboratory, sometimes on the designer's work setting but, in that case, on designers separated from all communication with their colleagues and their other usual information sources.

So, no study has been conducted until today on the professional design activity of solving a real, complex problem. As we may however reasonably suppose that this form of activity has its specificity compared to the one studied in limited settings (see Visser, 1987, for an illustration of this argument on a professional programmer's strategies), its study is required from a theoretical (problem solving) as well as an applied (assistance tool development) point of view. 
This text is the author's version of

Visser, W. (1988, 14-16 June). Towards modelling the activity of design: An observational study on a specification stage. Preprints of the IFAC/IFIP/IEA/IFORS Conference Man-Machine Systems. Analyisis, Design and Evaluation (Volume 1). Oulu, Finland, 14-16 June 1988.

Our research has been concerned with such an activity: we studied several stages in the process of the design of a real, complex, industrial project (see Visser, 1988, for a general presentation of this longitudinal study).

In this paper, we focus on a single stage in this design process, the specification stage. The aim of our study being ultimately the construction of a model of the design activity, we started to sketch out the general architecture of such a model based on the data we analyzed until now. In the present text we will describe this architecture at one particular level of the specification activity.

\section{METHOD}

\section{An Observational Study}

During a period of three weeks, we conducted, in a machine tool factory, full time observations on a mechanic involved in a specification task. We observed his normal daily activities without intervening in any way, other than to ask him to verbalize as much as possible his thoughts about what he was doing (Ericsson and Simon, 1984; Newell and Simon, 1972).

\section{The Observed Task}

The mechanic we observed had to specify the functioning of the operative part of an automatic machine tool installation. These specifications had to be produced in the form of a functional schema, and were to be given to the programmer of the control part of the installation.

The schema represents the functioning of the installation decomposed in "cycles". Next to a General Cycle presenting the functions of the whole installation, there is one cycle for each function presenting the operations fulfilling this function. Cycles as well as their functions or operations are defined each one by way of several "descriptors" (for example, their duration, their starting and ending conditions, and their temporal articulation with the other ones).

\section{Data Gathering}

We took notes on the mechanic's actions and collected all documents the mechanic produced during his work.

The notes concerned:

- the mechanic's productions and the remarks and comments he made;

- the order in which he produced the different documents, and how he gradually built them up;

- the changes he made;

- the information sources he consulted;

- the events we judged to be indicators of the subject meeting with difficulties.

The documents collected were: 
This text is the author's version of

Visser, W. (1988, 14-16 June). Towards modelling the activity of design: An observational study on a specification stage. Preprints of the IFAC/IFIP/IEA/IFORS Conference Man-Machine Systems.

Analyisis, Design and Evaluation (Volume 1). Oulu, Finland, 14-16 June 1988.

- the different versions of the functional representation;

- the diagrams and schemas the mechanic constructed for himself during his problem solving.

\section{The Observed Mechanic}

The observed mechanic had a professional experience of more than ten years in the machine tool factory working with the type of mechanical installation studied.

\section{RESULTS}

\section{A Theoretical Plan}

Before the mechanic started and after he had completed his task, we asked him to describe his activity. In both descriptions, he represents his activity in the same way, that is, as being guided by a plan, which has the structure of a tree he covers top-down, depth-first (see Visser, 1988, for a detailed description of this plan). According to his plan, the mechanic should deal with the different components of this plan (the cycles, and, inside each cycle, its functions or operations) one after another. So he would describe first the General Cycle with all the functions of the installation, then the cycle of the first function with all its operations, then the second one, and so on.

As components (that is, cycles, functions and operations) are defined by way of "descriptors", the preeminent goal of the mechanic is g1: searching for vi (where vi stands for vdk-ci , that is, the value of the descriptor $\mathrm{dk}$ of the component ci on which he is currently working). Having achieved this goal, that is, having obtained vdk-ci , he will turn to vdk+1-ci and so on. Only after having described ci should he start to deal with ci+1.

\section{The Actual Opportunistic Organization of the Activity: Deviations from the Theoretical Plan}

Observing his activity, we note however many deviations from the plan the mechanic described and from the pursuit of the goal g1: the description plan for the components and the searching plan for the values of the components' descriptors are abandoned.

\section{Abandonment of the description plan for the components}

- Components are abandoned, definitively or temporarily, before completion. Contrary to the mechanic's described plan, a component (that is, a cycle, function or operation) is not described entirely before the mechanic starts the description of another one. For example, at best half of the description of a cycle is described consecutively, that is, without interruptions for the description of other cycles. Except for the General Cycle (the one the mechanic starts with, presenting the functions of the installation), during the first processing of a cycle, not even half of its description is made.

- Addenda and modifications are made on past and future components. To take the example of the operations, only half of them are defined once and forever on their first processing. Some descriptors are assigned to an operation in anticipation. Others are only defined after the first partial description of a component, and still others are modified, after their first definition, one or several times. 
This text is the author's version of

Visser, W. (1988, 14-16 June). Towards modelling the activity of design: An observational study on a specification stage. Preprints of the IFAC/IFIP/IEA/IFORS Conference Man-Machine Systems. Analyisis, Design and Evaluation (Volume 1). Oulu, Finland, 14-16 June 1988.

Abandonment of the searching plan for the values of components' descriptors. Descriptors are assigned definitively to a cycle, a function or an operation in only a little more than half of the cases at their first processing.

In the following presentation of the psychological activity underlying these results, we will first lay out the general architecture of the activity on the level of component description. Our observations of the mechanic's activity will then be used for illustrating the different ways in which goal deviations occur.

\section{General Architecture of the Activity on the Level of Component Description}

Pursuit of the goal searching for vi. Even if often abandoned, searching for vi, that is, searching for the value of the descriptor $\mathrm{dk}$ of the component ci, is the central goal of the mechanic describing a component ci. For achieving this goal, the mechanic's knowledge base offers him several possible procedures.

The choice of one of these procedures will be made by way of control procedures. We formalize them as production rules, such as:

* RC1 - IF ci is classified as an element of a category $\mathrm{C}$ containing the element cj for which one already dealt with $\mathrm{dk}$,

THEN retrieve information from an information source relevant to dk-cj.

* RC2 - IF the information source selected, si, contains the value vi one is searching for,

THEN retrieve directly vi from si.

* RC3 - IF the information source selected, si, contains the information which permits to calculate vi,

THEN use this information to calculate vi.

If RC1 has been applied, the mechanic will retrieve, from the selected information source, information enabling him to calculate vi as an analogue of vj.

Certain control rules are more restrained with regard to their application domain. They apply, for example, only to one type of descriptor. For the "duration" of a component (cycle, function or operation), for example, the mechanic can judge that the one he arrived at (by calculating, transforming, or retrieving it directly) is an uncertain value (that is, the component's duration risks to be longer than can be foreseen in this study stage of the design). If so, AND IF the total cycle duration permits to, he can decide to increase vi with a certain amount $\mathrm{x}$ (some hundreds of seconds).

Different levels of the goal space at which occur deviations from searching for vi (g1). As long as the mechanic follows g1, different control rules establish which one(s) of the series of procedures in the goal space of searching for vi is (are) used to determine the value of the descriptor dk of the component ci.

Abandonment of g1 is also governed by control rules. It can occur at several levels of the goal space. 
This text is the author's version of

Visser, W. (1988, 14-16 June). Towards modelling the activity of design: An observational study on a specification stage. Preprints of the IFAC/IFIP/IEA/IFORS Conference Man-Machine Systems.

Analyisis, Design and Evaluation (Volume 1). Oulu, Finland, 14-16 June 1988.

- At the upper level, that is, at the level of component description: especially the goal taking into account new information (g2) (see below) risks to lead the mechanic to abandon g1. In that case g1 is abandoned even before the mechanic has engaged in one of the procedures for achieving it.

Another reason for abandoning $\mathrm{g} 1$ at the top level is translated by $\mathrm{RC} 4$, a control rule applying not only to g1:

* RC4 - IF achieving the goal gx is judged difficult,

AND IF this goal is judged to be achieved more easily later on,

THEN postpone the achievement of gx

AND take as goal $\mathrm{gx}+1$.

- Certain type of goal deviations can occur at different levels of the goal space. An example is a switch to the goal verification of $\mathrm{vj}(\mathrm{g} 3)$ (see below).

RC5 is a control rule which applies during processing of operations:

* RC5 - During processing of an operation Ox,

verify that $\mathrm{Ox}$ is physically realizable on the installation such as it has been designed.

If this verification leads the mechanic to conclude that $\mathrm{Oi}$ is not physically realizable on the installation such as it has been designed, he will interrupt the current definitional processing of Oi and resume the mechanical design of the installation.

- At one of the intermediate levels, that is, engaged in a procedure for realizing $\mathrm{g} 1$, this procedure - and thus $\mathrm{g} 1$ - can be abandoned. This can happen in several ways:

- by drifting away;

- by discovering an error or an omission on another component.

This kind of deviations occur mostly during the mechanic retrieving information from information source si. They engage the mechanic in the pursuit of a different goal which can be g2 or g3, but also error correction (g4a) or making up an omission (g4b) (see below).

Different types of goal deviations. g1 can be abandoned in two ways: either by switching directly to one of the following other goals:

- taking into account new information (g2);

- verification of vj (g3);

- error correction (g4a);

- making up an omission (g4b);

or by drifting, which not necessarily leads to a goal change, but often indirectly does. 
This text is the author's version of

Visser, W. (1988, 14-16 June). Towards modelling the activity of design: An observational study on a specification stage. Preprints of the IFAC/IFIP/IEA/IFORS Conference Man-Machine Systems.

Analyisis, Design and Evaluation (Volume 1). Oulu, Finland, 14-16 June 1988.

If, in general, the mechanic returns to his theoretical plan after one deviation step, sometimes it occurs that he still makes other deviations before coming back to $\mathrm{g} 1$. We will present a detailed example of such a sequence of deviations.

taking into account new information (g2). New information can be obtained

- incidentally:

- the design constraints can be modified;

- retrieving information from information source si, the mechanic can come across information not yet noticed until then;

- voluntarily:

- the mechanic, trying to solve a problem, consults a "specialist";

- the information obtained provides him with new knowledge he wants to use.

As we observed that the mechanic interrupts always his current description for taking into account the new knowledge he acquired which he judged as having repercussions for the descriptions he already made of previous dealt with components, we formulated RC6.

* RC6 - IF new knowledge is acquired,

THEN apply it immediately on past components.

An example of instantiation of this rule is the following.

The mechanic consulting a colleague electrician for the definition of the ending conditions of an operation $\mathrm{Oj}$, learns that

- a long operation is controlled physically by two cams,

and

- one has to use the control information provided by both cams to define the end of such an operation.

Applying this new knowledge, the mechanic modifies the ending conditions of all long operations which he defined until then.

verification of vj (g3). At several times the mechanic interrupts his description of an operation for verifying descriptions already made. These interruptions can result from having obtained new information (see the example given above), but can occur also without no apparent cause.

A rule translating the control of verification observed is

* RC7 - IF new knowledge is acquired,

THEN verify the elements this knowledge pertains to. 
This text is the author's version of

Visser, W. (1988, 14-16 June). Towards modelling the activity of design: An observational study on a specification stage. Preprints of the IFAC/IFIP/IEA/IFORS Conference Man-Machine Systems. Analyisis, Design and Evaluation (Volume 1). Oulu, Finland, 14-16 June 1988.

This kind of verification often leads the mechanic to error or omission discovery. If he decides to repair the error or omission noticed, he will engage in another goal change (g4a or g4b) (see below).

The ending condition(s) of a component being often (one of) the starting condition(s) of the next one, $\mathrm{RC} 8$ is a rule specific to these descriptors:

* RC8 - IF the starting condition of the component $\mathrm{cn}$ has been modified,

THEN verify the ending conditions of the component $\mathrm{cn}-1$.

error correction (g4a) or making up an omission (g4b). Goal change for pursuit of one of these goals is among the most frequent causes of plan-guided cycle construction abandonment. It is the retrieving of information on an analogue component that often leads to the discovery of an error or omission the mechanic decides to repair.

As we noticed already with respect to the verification of $\mathrm{vj}(\mathrm{g} 3)$, a switch to one of these two goals often occurs after the mechanic already changed his goal g1 for pursuing another goal as g3 or g2 (taking into account new information).

* RC9 - IF an error or omission is discovered,

THEN engage in error correction (g4a)or making up an omission (g4b).

drifting. Even if drifting not necessarily leads to a goal change, it often does, because it makes the mechanic to come across information he decides to take into account. Control rules for the drifting we noticed are, by definition, difficult to formulate. A hypothesis inspired by our observations is that drifting occurs especially during information retrieval for a problem solving not guided by strict information searching rules.

We will conclude this presentation of results by giving one detailed example of abandonment of $\mathrm{g} 1$, implying several goal changes.

A detailed example of goal g1 abandonment implying several goal changes. If the mechanic followed his theoretical plan, he should describe first, consecutively, all N1 operations of the first cycle, then all $\mathrm{N} 2$ operations of the second cycle, etc. (NB. All cycles do not necessarily have the same number of operations.)

Let us now have a look at the mechanic's real activity, while engaged in the description of the second cycle (cy2).

To define the eigth operation on this cycle, O8cy2, he decides to consult cy1 (the first cycle), to take example on it for the definition he already gave of O7cy1, the analogue of O8cy2 on cy1. Drifting away on the description of cy1, "his eye falls on" O1cy1. Dealing with O1cy1, he "thinks of" an omission on O3cy1, an operation which is in interaction with O1cy1. He repairs the omission on O3cy 1 and then returns to his description of O8cy2 on cy2 (with the information he needs for this description). 
This text is the author's version of

Visser, W. (1988, 14-16 June). Towards modelling the activity of design: An observational study on a specification stage. Preprints of the IFAC/IFIP/IEA/IFORS Conference Man-Machine Systems. Analyisis, Design and Evaluation (Volume 1). Oulu, Finland, 14-16 June 1988.

\section{CONCLUSION}

The general architecture we presented for the activity observed in a specification stage of design on the level of component description divides the solution space for a problem in different goal spaces.

Control procedures formalized as production rules govern the transitions

- from a goal

- to an information processing procedure pursuing its achievement

- or to another goal

and

- from an information processing procedure pursuing the achievement of a goal

- to another information processing procedure

- or to another goal to pursue.

The central goal space at the level of component description consists of a set of information processing procedures leading from this central goal g1, searching for vi, to its achievement, obtaining vi.

The articulation of the goal space g1 was presented as following a hierarchical organization inspired by the mechanic's description of his plan, but control rules for goal changes abandoning this plan were formulated to account for our observations of goal deviation. We do not hold, for the moment being, enough elements to conclude on the importance degree of the guiding of the activity by this plan. We observed however that

* many deviations from this plan take place;

* the activity has a strong opportunistic component.

Other observations, experimentally conducted or not, will have to be made to determine the respective contributions of (hierarchical) plan guiding and opportunistic factors.

The result that design is not an exclusively hierarchically organized plan-guided activity leads us to favor an opportunistic model which can incorporate the possibility for plan-guided contributions without being exclusively governed by this plan (see Hayes-Roth \& Hayes-Roth, 1979). The general architecture we sketched based on the data we analyzed until now is in all respects compatible with such a model.

\section{REFERENCES}

Bisseret, A. (1987). Towards computer-aided text production (Rapport de Recherche $\mathrm{N}^{\circ}$ 665). INRIA, Rocquencourt.

Carroll, J. M. \& Rosson, M. B. (1985). Usability specifications as a tool in iterative development. In H. Rex Hartson (Ed.), Advances in human-computer interaction (Vol. 1). Ablex, Norwood, N.J.. 
This text is the author's version of

Visser, W. (1988, 14-16 June). Towards modelling the activity of design: An observational study on a specification stage. Preprints of the IFAC/IFIP/IEA/IFORS Conference Man-Machine Systems.

Analyisis, Design and Evaluation (Volume 1). Oulu, Finland, 14-16 June 1988.

Eastman, (1969). Cognitive processes and ill-defined problems: a case study from design.

Proceedings of the First Joint International Conference on Artficial Intelligence. Washington, D.C..

Ericsson, K. A., \& Simon, H. A. (1984). Protocol analysis. Verbal reports as data. MIT Press, Cambridge, Mass..

Hayes-Roth, B., \& Hayes-Roth, F. (1979). A cognitive model of planning. Cognitive Science, 3, 275310 .

Newell, A., \& Simon, H. A. (1972). Human problem solving. Prentice-Hall, Englewood Cliffs, N.J..

Simon, H. A. (1973). The structure of ill-structured problems. Artificial Intelligence, 4, 181-201.

Visser, W. (1987). Strategies in programming programmable controllers: a field study on a professional programmer. In G. Olson, S. Sheppard \& E. Soloway (Eds.), Empirical Studies of Programmers: Second Workshop. Ablex, Norwood, N.J..

Visser, W. (1988). Giving up a hierarchical plan in a design activity (Rapport de Recherche INRIA $\mathrm{N}^{\circ} 814$ ). Rocquencourt: INRIA. 